https://doi.org/10.31713/m1104

\title{
DEVELOPMENT OF GEOTECHNOLOGICAL METHODS FOR STRENGTHENING THE DISTURBED ROCK MASS
}

\author{
Demin V. F. \\ Doctor of Technical Sciences, Professor, Karaganda Technical \\ University, Karaganda, Republic of Kazakhstan
}

Kamarov R. K.

Candidate of Technical Sciences, Professor, Karaganda Technical

University, Karaganda, Republic of Kazakhstan

\section{Zhumabekova A. E.}

$\mathrm{PhD}$, Senior Lector, Karaganda Technical University, Karaganda, Republic of Kazakhstan

Extended annotation. Objectives of the research: practical usage analysis of roof bolting in coal mines; mining and geological conditions assessment of the preparatory minings; research of the stress-strain state of the rock mass around the workings; development of technological schemes of anchorage; determination of the influence of anchorage technology on the operational characteristics of mining operations. The main idea is to develop geotechnological methods and test the strengthening effect on the disturbed coal-bearing massif during man-made processes. The result of the study is to provide safe conditions for maintaining mine workings, the stability of the immediate roof, reducing rock falls and increasing the service life of the support. Subject of research: operational underground workings of coal mines. Methodology: analysis of maintenance conditions; assessment of factors that negatively affect the conduct of mining operations; determination of the manifestations of rock pressure; development of methods and means of active fastening of the broken coal-bearing array. The purpose of the work is to develop technological schemes for conducting preparatory workings of coal mines using anchoring in difficult mining and geological conditions. Research results: development of geotechnological methods for strengthening the disturbed massif. A method of two-level fixing with a complex overlap of the roof fixing zones over the workings, with the imposition of strengthening zones in the resulting rock arch, has been developed; a method for fixing the excavation in the zone of influence of cleaning works by means of stitching unstable rocks of the immediate roof and then fixing the created artificial "bridge" to the strong rocks of the main roof; mesh tightening to perceive the load from rocks in the space between the anchors and prevent the precipitation of rock mass; a method for combating soil heaving of preparatory workings by spacer blocking the disturbed rock blocks with power spacer modules. 
Introduction. The world experience of advanced coal-mining countries (USA, Australia, China, etc.) shows that effective and reliable fastening of capital and preparatory workings can be provided by using steel-polymer anchors with a bearing capacity of at least $100-130 \mathrm{kN}$. Monitoring of the use of anchor support in coal mines shows that, in accordance with existing regulatory documents, it is used both as the main and auxiliary support in combination with metal frame pliable support.

The problem of effective fastening of workings in mines is not completely solved, which is due to the fact that the currently used method of supporting excavation workings with frame metal arch supports with reinforcement posts is very labor-intensive and metalintensive.

Therefore, one of the most relevant directions in the coal mining industry is the development of a technology for fixing excavation workings, taking into account the technogenic state of the nearcontour massif in areas of increased displacement due to various types of disturbances in the occurrence of host rocks and changes in the elements of the occurrence of coal seams.

\section{Factors that negatively affect the conduct of mining opera- tions and the development of coal seams}

The rock pressure depends on the depth of the excavation, the physical and mechanical properties of the rocks in the massif (strength, collapsibility, controllability, fracturing, etc.), the angle of occurrence and thickness of the layers, the methods of coal excavation, the size of the section of the excavation, the mechanical characteristics of the support and other parameters.

The factors that complicate the conduct of treatment and preparatory work include various geological disturbances. Geological disturbances in the occurrence of coal seams are of two types, formed during the occurrence of the formation or in the formation after its occurrence.

Violations of the first type include: formation wedging - a gradual decrease in the thickness of the formation, sometimes up to its disappearance; formation swelling - a sharp increase in the thickness of the formation in a certain area. 
Violations of the second type include: upsets, offsets, displacements, folds, splits.

Upwelling is the displacement of rock along a fault associated with the uplift of one block of the earth's crust relative to another (Fig. 1).

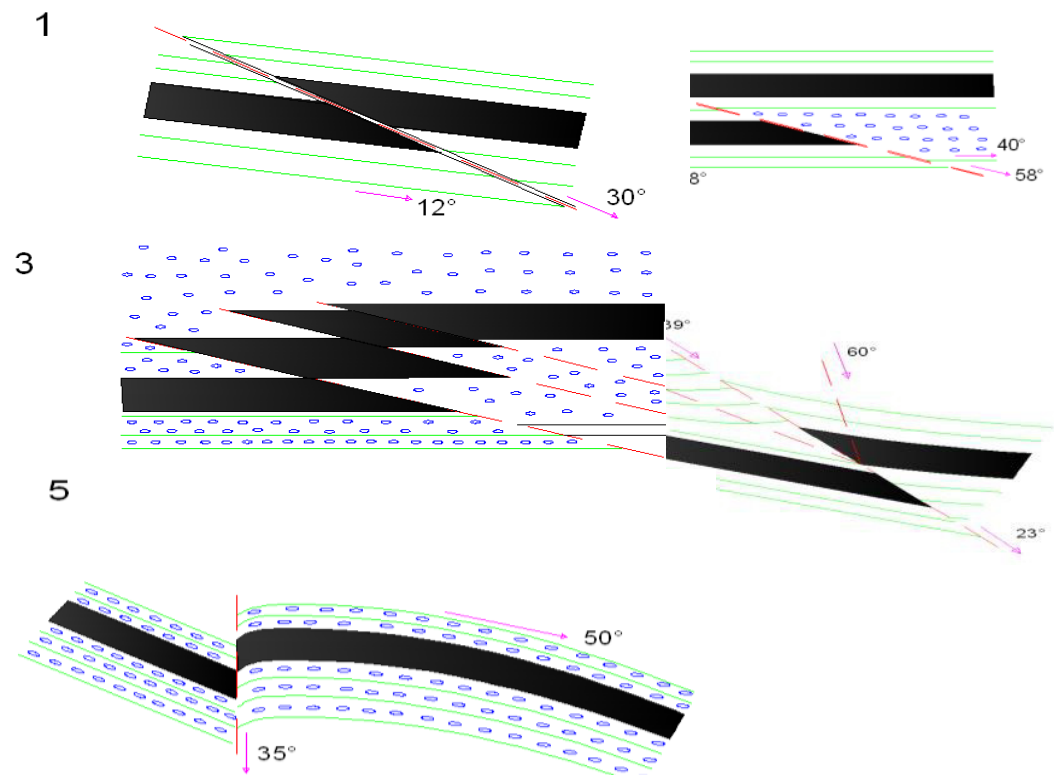

Fig. 1. Low-amplitude upswings: 1 - converging upswings on the fall; 2 - horizontal upswings; 3 - a series of horizontal upswings; 4 - diverging upswings on the fall to the flank destruction; 5 - sliding downswing

With a gentle displacement, the gap is attributed to the thrust. Usually, $45^{\circ}$ (up to $60^{\circ}$ ) is taken as the smallest angle of incidence of the reset shifter. When the angle is between 45 and $60^{\circ}$, the term "upswing" is used. In general, upsets are formed under conditions of tangential compression, often due to folding. The geometric effect of the upswing is to reduce the earth's surface [1].

Discharges - tectonic disturbances in which the surface of the fault (the displacer) is inclined towards the location of the lowered rocks (Fig. 2 and 3).

The reset is determined by the fact that its hanging wing is shifted down relative to the recumbent one. This type of dislocation is asso- 
ciated with the stretching of the rocks involved in the movement and is characterized by the absence of any compressive stresses, which are usually associated with the formation of thrusts and displacements $[2,3]$.

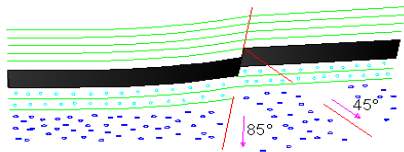

3

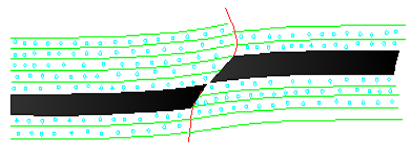

5

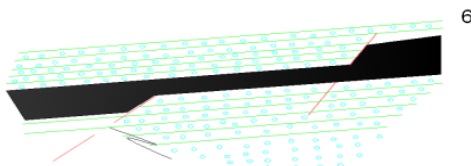

4
2
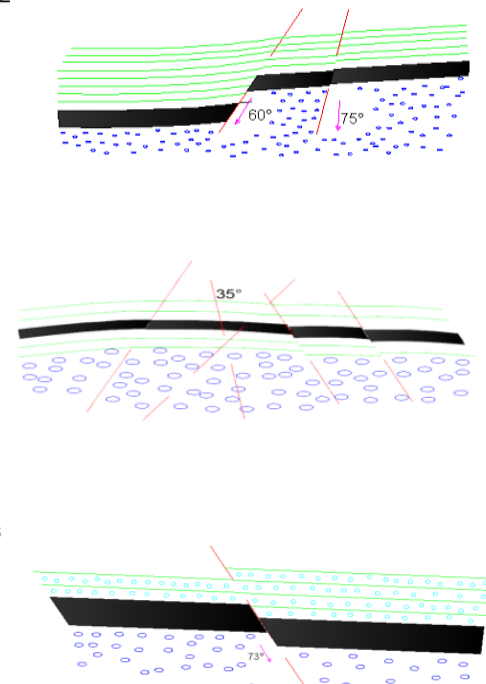

Fig. 2. Low-amplitude discharges: 1 - divergent discharges by fall; 2 - series of discharges by height; 3 - convergent diagonal discharges by fall; 4 - group of discharges by compression; 5 - convergent discharges by fall; 6 - horizontal discharges

Displacements are sub-vertical discontinuities whose displacements occur in the horizontal direction (Fig. 4). The displacements differ in the wings, the shifter, the angle of inclination of the shifter, and the displacement amplitude. In relation to the strike of disturbed rocks, displacements, as well as discharges, can be longitudinal, oblique, or diagonal and transverse [4].

1
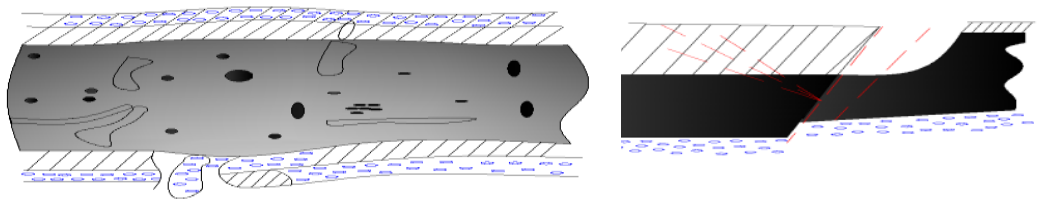
3

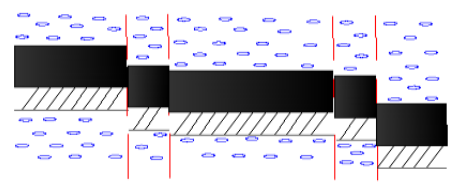

4

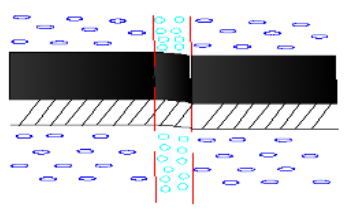

5

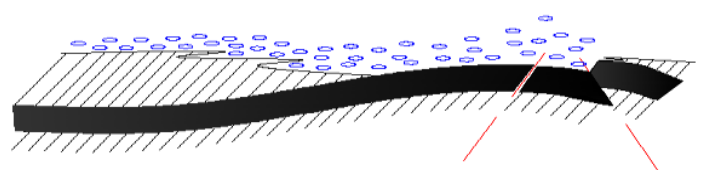

Fig. 3. Low-amplitude extended discharges: 1 - height discharges; 2 - horizontal discharges; 3 - a series of discharges; 4 - a close group of discharges; 5 - discharges and discharges that are close to each other

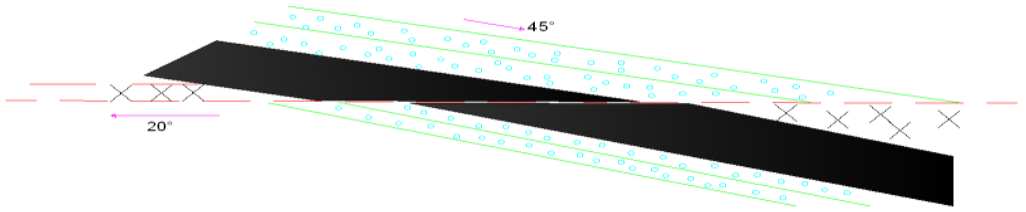

Fig. 4. Horizontal shifts in the fall

Folds - bends of rock layers usually with an alternation of convex (anticlines) and concave (synclines) forms, the most widespread and pronounced within the folded systems [5].

In the zones of influence of geological disturbances, a decrease in the rate of penetration by 2-3 times was recorded, as well as an increase in the cost of carrying out and repairing workings. This is mainly due to significant fallout with a height of up to $5 \mathrm{~m}$, associated with intense fracturing of the rock mass.

\section{Manifestations of rock pressure during mining operations}

Conducting underground workings changes the state of rocks with the formation of zones of high and low stress. The phenomena associated with the deformation, displacement, destruction of the massif, the pressure of rocks on the support, are manifestations of mountain pressure, which depend on the mining and geological conditions and technological features of the development. 
The nature of the stress distribution around the mine depends on its shape and the ratio of the cross-section dimensions. In the roof and the soil of the workings, when the lateral spacer is less than one, there are tensile forces

$$
\sigma_{\min }=k_{1} \frac{v}{1--v} \gamma H
$$

where $k_{1}$ is the coefficient of concentration of tensile stresses; $v /(1-v)$ - coefficient of lateral expansion; $v=0.1+0.4$ - Poisson's ratio; $V$ density of rocks, $\mathrm{t} / \mathrm{m}^{3}$; H-depth from the surface to the mine, $\mathrm{m}$.

As you move away from the contour of the mine deep into the massif, these stresses decrease to zero, and then turn into compressible and approach the original value

$$
\frac{v}{1-v} \gamma H
$$

There is a significant increase in compressive stresses in the sides of the mine

$$
0_{\max }=k_{2} \cdot \gamma H
$$

where $k_{2}$ is the compressive stress concentration coefficient.

As you move deeper into the array, the compressive stresses decrease to their original value $\gamma H$.

The stress concentration around the mine is limited to a certain zone, the dimensions of which are $(3+5) 1$, where 1 is the largest linear size of the mine section. Near the outcrop contour, stresses can exceed the ultimate strength of rocks, resulting in their destruction or plastic flow.

The area of influence of mining is a part of the rock mass, within which the displacement, deformation and destruction of rocks occur. The area of influence of the mine work, adjacent directly to its contour, within which the stresses are higher than in the untouched massif, is called the reference pressure zone.

The nature of the formation of the area of influence of mining, all other things being equal, depends on the physical and mechanical properties of rocks.

The rocks of the roof, sides and soles are stable. In this case, 


$$
\begin{aligned}
& k_{1 \frac{v}{1-\nu}} \gamma H<k_{c} \sigma_{p} \xi \\
& k_{2} \gamma H<k_{c} \sigma_{c \varkappa} \mathrm{E}
\end{aligned}
$$

where $E$ is the coefficient of long-term strength; $\sigma_{p}, \sigma_{c \varkappa}$ - the ultimate strength of rocks, respectively, for tension and compression under the conditions of a biaxial stress state.

If the conditions are met, no dangerous deformations are formed in the outcrops.

The rocks of the roof of the mine are unstable, and the sides and the soil are stable

$$
\begin{aligned}
& k_{1 \frac{v}{1-v}} \gamma>k_{c} \sigma_{p} \xi \\
& k_{2} \gamma H<k_{c} \sigma_{c \varkappa} \xi
\end{aligned}
$$

In this case, the roof rocks will be destroyed. With the development of fracturing in the area adjacent directly to the roof of the mine to the roof of the mine. Individual sections of the rock lose their connection with the array and fall out. The gradual collapse of the rocks continues until the formation of an irregular shape surface, which approaches the collapse arch. Outside of it, a vault of natural balance is formed.

The rocks in the roof and in the sides of the mine are unstable, in the soil they are stable

$$
k_{1} \frac{v}{1--v} \gamma H>k_{c} \sigma_{p} \xi ; \quad k_{2} \gamma H>k_{c} \sigma_{с ж} \xi
$$

Fig. 5 and 6 show, respectively, the schemes of hanging on anchors and forming using anchors of the load-bearing structure in the roof of the mine.
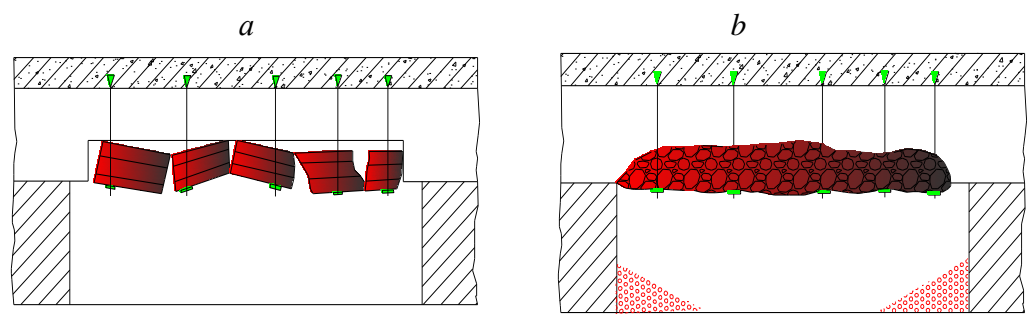

Fig. 5. The scheme of hanging on anchors: a-individual blocks; b-the disturbed layer of the immediate roof to the stable overlying rocks 
$a$

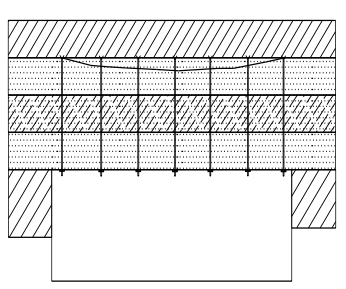

$b$

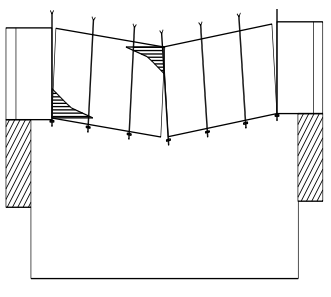

$c$

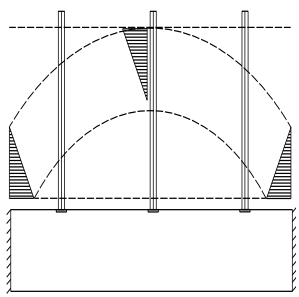

Fig. 6. The scheme of formation using anchors of the load-bearing structure in the roof of the development in various forms: a-composite beams; $\mathrm{b}$ and $\mathrm{c}$ - respectively, three articulated arches and arches

Fig. 7 shows the technological schemes for fixing the contours of mining workings.

The lower layer of the rocks of the immediate roof of the formation can have different stability both during coal excavation (separation of coal from the massif), and after a certain period of time after its exposure.

The degree of stability of the rocks of the lower layer significantly depends on the safety of labor, the efficiency of coal excavation, the choice of the type and design of the bottom-hole support, sometimes the method of roof management, etc. In the classification of the DonCSI [6], there is a typification or division of the rocks of the lower layer of the direct roof of the layers into 5 categories of stability (they are usually designated B).
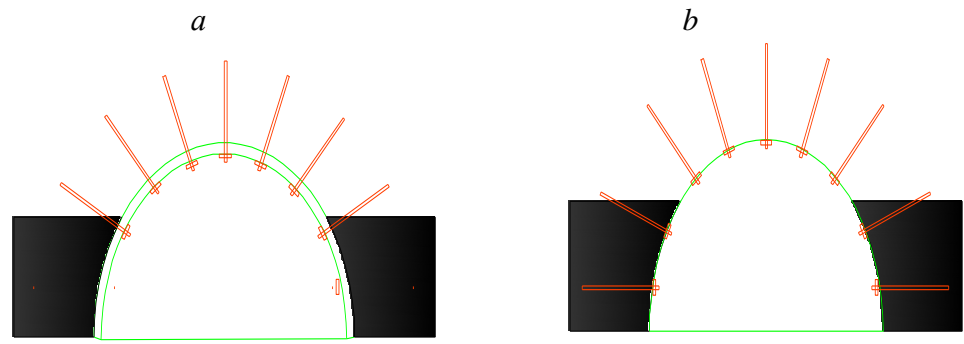

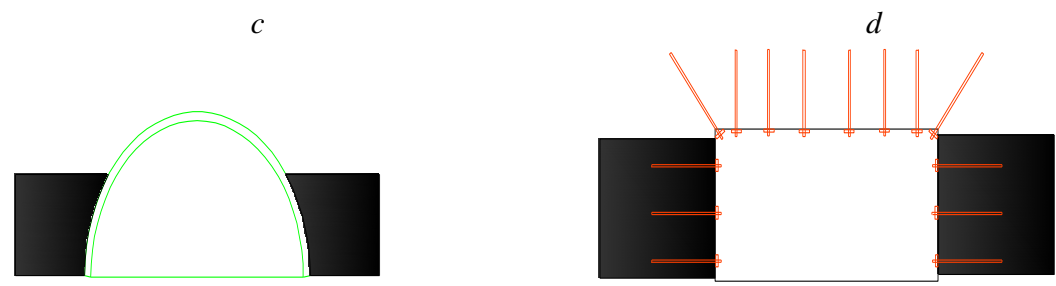

Fig. 7. Technological schemes for fixing the contours of mine workings: a-fixing the arched shape with combined support (metal-arched support with anchors in the roof); b-fixing the arched shape with combined mixed support (metal-arched support with anchors in the roof and sides); c-fixing the arched shape with metal-arched support; d-fixing the rectangular shape with anchor support

Recently, due to the increasing complexity of mining and geological conditions of development, due to the increase in the depth of mining operations and the initial development of layers with favorable conditions of occurrence, the cost of production increases; productivity in treatment and preparatory faces is at a low level, the labor intensity in conducting, maintaining and repairing mining workings increases, the ash content of extracted coal in treatment (33\% or more) and preparatory work (37-41\%) and the negative trend of their growth.

One of the limitations for the wider implementation of anchor support in the mines of the Republic of Kazakhstan, the Karaganda coal basin is the lack of a regulatory framework that allows taking into account the specific geomechanical situation, mining development schemes and experience in using anchor support, it is justified to accept the parameters of fixing mine workings. The stage for implementation in the creation of standard mining schemes is the formation of technological schemes for fixing workings using anchor support. A systematic analysis of the passports for fixing the workings of the mines of the Karaganda coal basin using anchor supports allowed us to form some of the following passports for fixing the workings with anchors for various schemes of mining development and their purpose.

Technological schemes for conducting and securing mining workings largely depend on the complexity of the mining and geological conditions of development and the emerging mining and 
technical factors in the conditions of the mines of the Karaganda coal basin.

Below are a number of passports for fixing mine workings, depending on the conditions of their operation.

The technology of working out with the use of metal-welding pliable support is shown in Fig. 8. These workings are subject to intense deformations and therefore are often re-anchored and the soil rocks are undermined.

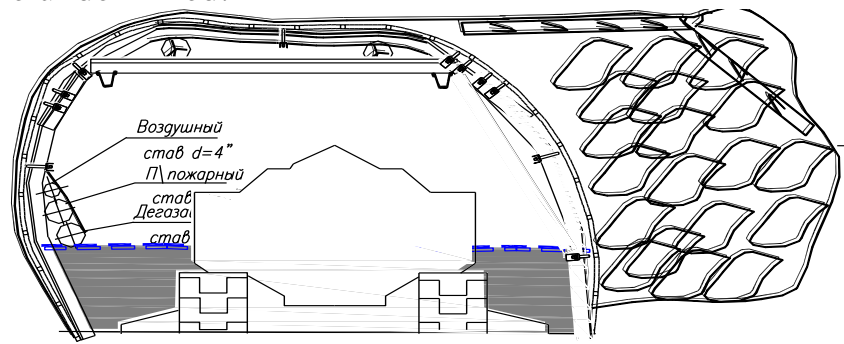

Fig. 8. Operational passport of carrying out, fastening and undermining during operation of the conveyor drift $33 \mathrm{k} 8-7-1 \mathrm{z}$ in the conditions of the mine named after Kuzembayev of the Karaganda coal basin

Due to the fact that during the operation of the workings there are disturbed and unstable zones of the mountain enclosing near-contour rocks, passports of workings with a combined attachment are used (Fig. 9).

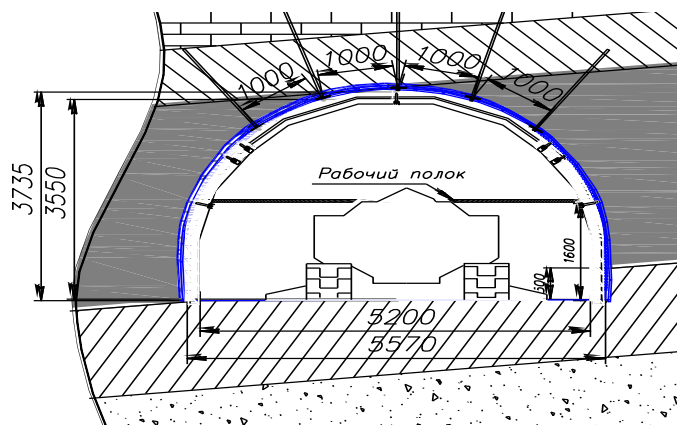

Fig. 9. The passport of the fastening of the conveyor drift $34 \mathrm{k} 8-7-\mathrm{z}$ in the conditions of the mine. Kuzembayev of the Karaganda coal basin 
Based on the general state of this problem, theoretical and experimental studies in the field of anchor anchoring of preparatory workings were carried out to solve the following tasks: analysis and evaluation of the effectiveness of existing equipment and technology of anchor fastening for various mining and technological conditions, justification of the prospects and conditions for the use of this technology; development and implementation of steel-polymer anchors of a new technological level, assessment of their effectiveness in improving the stability, reliability and safety of preparatory workings; justification of technological schemes for the installation of steelpolymer anchorage with the inclusion of the process in the tunneling cycle in order to prevent the stratification of rocks; development of a methodological approach to assessing the economic efficiency of the use of new types of anchorage created.

The method of two-level fixing with overlapping of the roof fixing zones above the workings

The maintenance of the roof for the entire duration of the mining operation is achieved by drilling and installing two levels of anchors. Anchors of the first level are steel-polymer anchors 5 (for example, 2-3 m). Second-level anchors rope anchors 4 (for example, 3-7 m). In the area of the immediate roof of the mine, in each area of the anchorage (more precisely, steel-polymer and rope), zones of strengthening of the roof are created. The anchors of the two levels are installed at such a distance from each other that the strengthening zone of the first level 1 is fixed with the strengthening zone of the second level 2 in the joint zone of strengthening zones 1 and 2 of zones 3 . Thereby creating a large area of the direct roof connected to each other by less and stronger rocks, and we achieve a large load-bearing capacity of the roof in time-Fig. 10.

\section{Method of fixing the excavation in the zone of influence of cleaning works}

The objective of the technical proposal is to increase the stability of the immediate roof on strategically important mining sites, to increase the safety of work on deep horizons by stitching unstable rocks of the immediate roof and then fixing the created artificial "bridge" to the strong rocks of the main roof.

Technical result: improvement of the technical condition of the anchor support, creation of conditions for maintaining a constant 
cross-section of the workings, ensuring the greatest stability of the immediate roof, reducing rock falls and increasing the service life of the support.

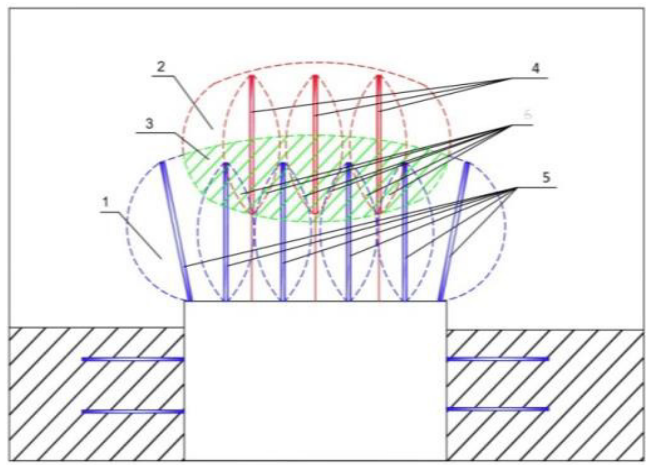

Fig. 10. The method of two-level overlapping of the roof fixing zones over the development: 1 - zone 1 (zone strengthening of the roof with steel-polymer anchors); 2 - zone 2 (zone strengthening of the roof with rope anchors); 3 - zone strengthening of the connection of zone 1 (zone strengthening of the roof with steel-polymer anchors) and zone 2 (zone strengthening of the roof with rope anchors); 4 - rope anchors; 5 - steel-polymer anchors; 6 - zone of maximum strengthening of the connection of zone 1 and zone 2

The technical result is achieved due to the fact that, when an artificially direct roof gets a certain additional margin of safety in the reference pressure zone, the rock mass created in this way is fixed with the help of rope anchors deep lying to the stronger rocks of the main roof. This creates the effect of contouring and strengthening the working plane and reduces the pressure on the support-Fig. 11.

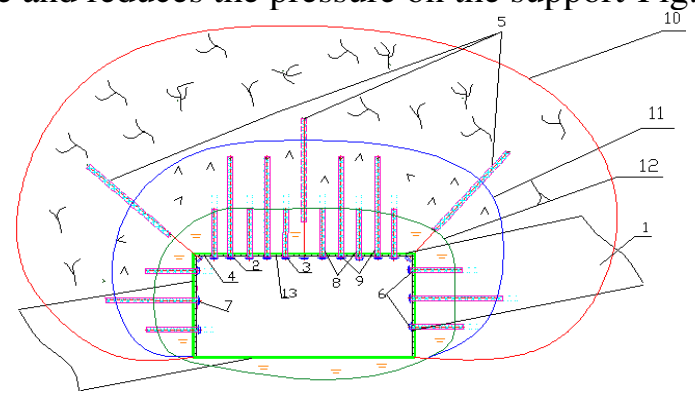

Fig. 11. Method of fixing the excavation in the zone of influence of cleaning works 
This method of fixing is based on creating a connection between the immediate roof, which is unstable rocks, with the main roof, which is represented by stable strong rocks, such as mudstone or sandstone, to which the immediate roof is attached.

This connection is made by laying 3 levels of anchors: shallow anchors of the 1st level $(6,8)$ (fasten the immediate roof), deep anchors of the $2^{\text {nd }}$ level $(7,9)$ (create a connection between the immediate roof anchored by the 1st level anchors and the main roof) and deep-lying anchors. Deep-lying anchors are usually rope anchors with a length of at least 5-7 m. For fixing the first level, steelpolymer anchors with a length of $2.4 \mathrm{~m}$ are used, and for fixing the second level, steel-polymer anchors with a length of $3.5 \mathrm{~m}$ are used.

Three zones are created around the workings: reference pressure (12), elastic deformations (10) and plastic deformations (11), surrounding the workings with the anchors of the $1^{\text {st }}, 2^{\text {nd }}$ and $3^{\text {rd }}$ levels in relation to each other and to the workings.

Fixing begins with the frill of the face, namely the roof and sides of the workings. Then the roof anchors of the first level (8) are installed with full filling. After that, the roof anchors of the secondary level (9) and the side anchors are also installed with full filling. Next, deep-laid rope anchors (5) with incomplete filling of the hole are installed. All anchors are fixed in the hole with a solution obtained when the anchor breaks the capsules that are deliberately introduced into the hole. The number of holes in each hole is determined by the passport of the face mounting.

After the solution has solidified, a pressure plate is put on the anchor, which is fixed with a nut and tensioned.

Between the strip and the plate (2) with the tension nut (3), a cone-shaped spacer is installed, which, when the load is perceived, ensures the pliability of the support due to its deformation.

\section{Mesh puff}

The technical result consists in the reliable fixing of the array of enclosing rocks, improving the design, due to the reliable connection between the sheets of mesh tightening by means of a metal rod (Fig. 12).

The task is achieved by the fact that the mesh tightening for fixing mining workings, made in the form of sheets with diamondshaped openings directed towards each other, characterized in that the last row of diamond-shaped openings, has spherical cavities 
made under the diameter of the metal connecting rod, for connecting and fixing the sheets of mesh tightening among themselves.

$a$

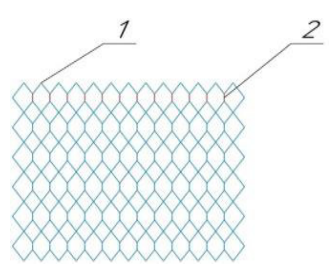

$b$

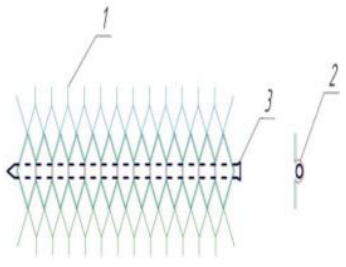

Fig. 12. Mesh tightening

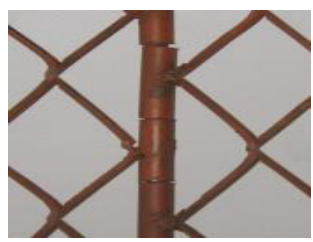

All existing types of anchors are divided into two categories according to the purposes for which they are used: first-level anchors (up to $2.5 \mathrm{~m}$ in length) for fixing the contours of mine workings, and second - level anchors (3-5 $\mathrm{m}$ in length or more) for fixing the joints and in special mining conditions (stress, overhanging coal massifs, etc.).

In order to increase the efficiency of fastening and ensure the long-term stability of preparatory workings with the use of steelpolymer anchors, it is necessary to continue research and theoretical justification of methods for calculating the parameters of fastening and checking the results in different mining conditions of coal mines.

It is possible to use various types of threaded surface of anchors, both metric and rolled, which makes it possible to increase the manufacturability of their manufacture and the load-bearing capacity of the anchor support - Fig. 13.

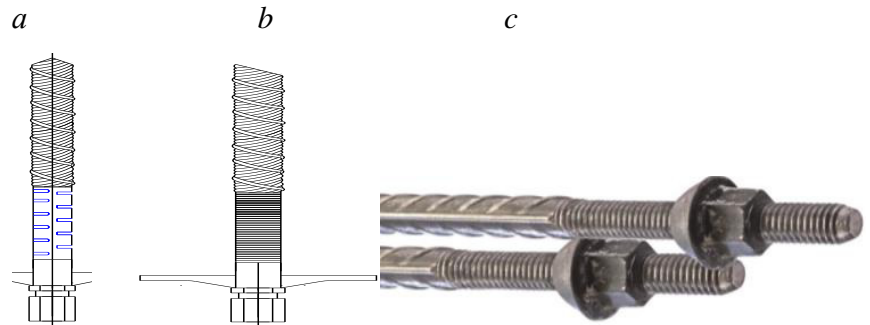

Fig 13. Anchors with an internal thread $(a)$ with a chisel end $(b)$, an external metric

(at the mouth) with a beveled end and its photo (c)

\section{Soil heaving and process flow diagrams to prevent soil rock blowing}

The stability of the soil of mine workings depends on a number of mining-geological and mining-technical factors, the most important of which are: the depth of work, the power and angle of fall of the 
formation, the moisture content of coal and the host rocks, the disturbance of the deposit, the physical and mechanical properties of the side rocks, as well as their combination in the array, the adopted development system, the length and speed of movement of the treatment face, the methods of protection of the workings, the parameters of the accepted support of the workings, the quality of its fastening, etc.

\section{Method of combating soil heaving in preparatory work}

In workings that are not affected by cleaning operations (the first type of deformation), the deformations of the rocks of the soil layers consist in a slight expansion, which is smaller in magnitude than the relative longitudinal deformation of the rock $\left(15 \cdot 10^{-3} \mathrm{~m}\right)$. Complete attenuation of deformations is observed after 150-300 days.

In the second type of deformation, a zone of destroyed rocks is located near the contour of the soil.

The coefficient of destruction of rocks in it increases with time, but this increase has a decaying character. The size of the destroyed zone reaches 2-3 m, and the expansion coefficient of rocks is 1.02-1.03. Further beyond the fracture zone to a depth of 5-6 $\mathrm{m}$ is the zone of creep deformations (elastic-viscous deformations).

The nature of rock deformation in this zone is also decaying. The relative deformations of the layers are $(10-15) \cdot 10^{-3} \mathrm{~m}$, i.e. 2 times and not less than the deformations in the fracture zone.

A comparison of the displacements along the width of the excavation shows that the intensity of deformation of soil rocks in the center of the excavation is slightly higher than on the sides [7-14].

Fig. 14 shows the relative deformations of the soil rock layers over time from the contour deep into the massif.

\section{Conclusion}

The development of geotechnological methods and testing of the strengthening effect on the disturbed coal-rock mass during manmade processes were carried out. 


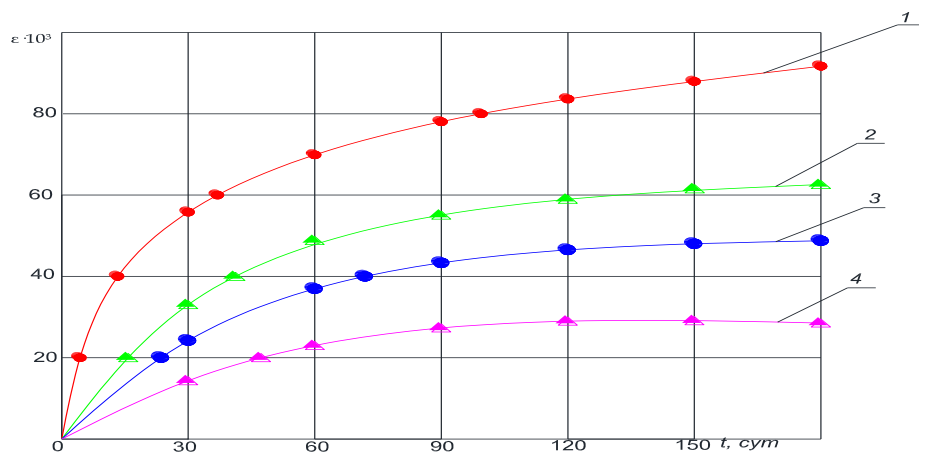

Fig. 14. Relative deformations of soil rock layers in time from the contour deep into the massif: 1 - $1 \mathrm{~m} ; 2$ - from 1 to $2 \mathrm{~m}, 3$-from 2 to $3 \mathrm{~m} ; 4$-from 3 to $4.5 \mathrm{~m}$

The factors that negatively affect the conduct of mining operations and the development of coal seams are analyzed. The manifestations of rock pressure during the preparatory workings are investigated.

The complex of factors affecting the stability of the workings fixed with anchor support, the schemes of hanging on anchors and forming a load-bearing structure in the roof of the workings using anchors, and the technological schemes of fastening the contours of the workings are evaluated.

The technology of conducting treatment works is considered. Usually, in a complex and in a relationship, the geomechanics of conducting work, the possibility of using the most advanced technical means (machines and equipment) and the rational alignment and sequence of all operations are taken into account.

When conducting mining operations on unstable subsurface rocks, the formation of cracks, splits, deformations and destructions of the weakest layers of the roof is observed, which requires additional technological measures to strengthen the lower layers of the roof of the development and reduces the pace of its implementation.

In this regard, a method of two-level fastening with a complex overlap of the roof fixing zones above the excavation, with the imposition of hardening zones in the resulting rock formation; a method 
of fixing the excavation in the zone of influence of cleaning operations by stitching unstable rocks of the immediate roof and then fixing the created artificial "bridge" to the strong rocks of the main roof; mesh tightening to perceive the load from rocks in the space between the anchors and prevent the precipitation of rock mass; a method for combating soil heaving in preparatory workings by spreading the broken rock blocks with power spacer modules.

\section{References}

1. Industry instruction on the use of frame and rock bolts in the development workings of coal and shale mines. - M .: IGD im. A.A. Skochinsky, 1985.- 64 p.

2. Shevyakov L. D. On the problems of studying rock pressure in connection with the demands of industry // Coal. - № 1, 2. 1997. - S. 34-37.

3. Carr F. Recent innovations in rock anchoring in the mines of the Government of the United Kingdom // Reports at the anchoring symposium. - London, 1984.- S. 268-281.

4. Ulrich L. Design basis for rock pressure control with combined support in stratal drifts. Gluckauf. - 2002, March. - S. 16-20.

5. Shemyakin I.I., Fomin E.V., Fedorov E.V. Improvement of the technology of conducting and securing mine workings at the Instinskaya mine // Coal. 2001.№. 2. - P. 6-10.

6. Kulasek M. Program for calculating rock pressure and convergence "Conversys". Commercial offer (Germany). - Karaganda, 2011.- 1 p.

7. Dontsul N.F. Some questions of the mechanics of a layered medium. - SPb .: ZAO Print-Express; St. Petersburg Mining Institute, 2009. - 379 p.

8. Altonian $\mathbf{P}$. Anchor fastening in the mines of the Karaganda basin. Presentation - 55 slides / ArcelorMittal. AC-R03. 2008.- 35 p.

9. Seedsman R. Review of anchoring in the mines of Karaganda / ArcelorMittal. 2010.- 35 p.

10. Instructions for the calculation and use of roof bolting in the coal mines of Kuzbass. - SPb .: JSC "VNIIMI", 2011. - 150 p.

11. Guber O. Development and delivery of digital modeling tools. Commercial offer. - Karaganda, 2011.- 10 p.

12. Katsaga T.Ya. Parametric modeling. - Karaganda: Sanat, 2004 .- 65 p.

13. Katsaga T.Ya. Modeling of the state of workings in the sinking and in the zone of influence of the cleaning work FLAC 3D. Commercial offer (USA). Karaganda, 2011.- 10 p.

14. Zabrodin A.S. On the assessment of disturbance of coal seams // In the book Geology of coal deposits.-Moscow: Nauka, T. 1, 1969. - P. 45-49. 